\title{
An Economic Analysis on System of Limited liability
}

\author{
Rui-Na Liu \\ (The People's Bank Of China ZhengZhou Training Institute)
}

Key words : System of limited liability; Social responsibility; Influence; Economics

\begin{abstract}
For a long time, the system is excluded from economic analysis as a premise frequently. In fact, not all systems are perfect, not everyone can benefit from it. Limited liability is this also. In view of this, this paper attempts to give an economic analysis on system of limited liability. First of all, this paper analyzes the necessity of limited liability; then clarifies the different effects on different social strata; finally, evaluates the system and offers its further direction.
\end{abstract}

Effective institutional arrangements is the booster of economic development; Reasonable system is critical to develop enterprises. A limited liability company is dominant in today's enterprise form, limited liability is the essential characteristics of modern enterprise system. Therefore, how to recognize limited liability system objectively, what is the difference between the system of social strata, how to improve and minimize the negative effects of this system and other issues of research, is important to improve the operational performance of the system, to establish and perfect modern enterprise system, to our country economy undoubtedly ,and is important to healthy and sustainable development.

Limited liability system is a kind of behavior rules, involves broad areas , embodies the economic, legal, social, political and other aspects. This article analyses the value of the limited liability system and existing problems from the angle of economics mainly. From the simple quotation, part one expounds on the historical inevitability between the connotation of the limited liability system and the evolution of enterprise form , the second part analysis of limited liability system to different people, the third part summarizes brief conclusion and points out the direction for the further development of limited liability system.

\section{The connotation and evolution of the limited liability system}

There are different views about the meaning of limited liability. The first view think limited liability is company's liability, the second view think limited liability is responsibility of shareholders to creditors, the third view think limited liability is limited to its investors liable to one's shareholder. In fact, for the limited liability ,we can't understand independently, we should know it comprehensively, in this way, we can avoid a lot of unnecessary disputes.

Limited liability is the mainstream i enterprises, and the essential characteristics of modern enterprise system. So why unlimited liability will evolve as limited liability, why limited liability is welcomed , and why unlimited liability is shrinking in the development of market economy? Here we use the famous prisoner's game to analyze it. Assuming that there are two types of investors A and $\mathrm{B}$, each person must make decisions independently in the form of limited liability or unlimited liability, both sides pursue their own profit maximization.

When A investor choose limited liability, B investor choose unlimited liability, this will become a combined company. In this situation, if the investment fail caused by some cases, the A investor 
losses two units, B investors losses six units.Also, as A investor choose unlimited liability, class B investor choice limited liability, this form is still the combined company. If the investment fails, the A investor losses six units, B investors losses two units. When both A and B investors choose unlimited liability, the company is the unlimited liability company, once the company losses, each type of investors' losses eight units. When both A and B investors choose limited liability, at this time the company is a limited liability company, once the investment fail, each type of investor losses one unit. So, in this game, the Nash equilibrium is $(-1,-1)$, that is, every one loss one unit, it is the best choice for two classes of investors.As shown below:

\section{Stakeholders B}

\section{Unlimited liability limited liability}

\begin{tabular}{l|l|l|}
\cline { 2 - 3 } Unlimited liability & $-8,-8$ & $-6,-2$ \\
\multirow{2}{*}{ limited liability } & $-2,-6$ & $-1,-1$ \\
\hline &,--- \\
\hline
\end{tabular}

Figure 1 Two types of investors in the choice of game between the limited liability and unlimited liability

Therefore, from the view of economic benefit, either class A or class B, most people would choose limited liability. This shows, the investors choose limited liability is clearly superior to unlimited liability. The emergence of the limited liability of is the inevitable result of market . In addition, the unlimited liability has high risk investment, difficult to raise capital and high difficulty transfer of equity, etc, these deficiencies make unlimited liability company is not adapted to the development of market economy more and more, and it is declining finally. However, in contrast, limited liability company is developing very fast, has occupied the dominant position in the form of enterprises. So, the emergence of limited liability is a big leap in the history of enterprise forms. Limited liability is the result of practice, also conforms to the requirements of the unity of history and logic. From the history of enterprise form, form the beginning is infinite companies, then combined company, the final evolution limited liability. So, if limited liability is the inevitable result of market decisions, and conforms to the requirement of unity of history and logic, it wasn't perfect? all social strata can benefit from it? The following section will detail these problems.

\section{Impacts on all walks of life in the society of limited liability system}

Limited liability system develops quickly,and has occupied the dominant position in the form of enterprises. It is a big leap in the development history of enterprise form, is the greatest inventions based on the economic purpose, creates a lot of productivity, proves the value of its existence . But just as everything has two sides, it plays the positive function one side,but it can't avoid another pair of contradiction. The paradox of one side is the limited liability of shareholders, the other is the interests of the creditors, customers and other stakeholders. Because the debts of the corporation not only involves the interests of investors, also involves the interests of the creditors, consumers, such as the rights and interests of a lot of interest subjects. Limited liability system limit the investor's risk within the scope of the contract in advance, but don't protect the 
rights and interests of creditors, customers and other stakeholders. Visible,when the limited liability system appeared, it also set up an unbridgeable walls between stakeholders and other interest subjects. How to solve the contradiction has become an important problem faced by the system. From these analyses, we can see that,the limited liability system has different effects to all walks of life. Therefore, the following specific will analyze its impact on different classes of society.

\subsection{The impact on the shareholders (investors).}

2.1.1Improve investment enthusiasm of the shareholder. Limited liability system can control risk effectively, encourage investment , and overcome the constraints of the unlimited liability form. Compared with unlimited liability, the shareholders bear unlimited joint and several liability for the debts of the company, in the limited liability company, the shareholders is limited to the amount responsible for the company's debts, it disperse the risk, the investor's risk is controlled within the scope of investment, this situation gives some shareholders investment security guarantee. So it can reassure investors, enhance their investment confidence, increase their investment enthusiasm, and then is beneficial to wide absorption of social capital, is conducive to raising large amounts of capital, is advantageous to the development of economies of scale.

2.1.2Reduce the supervision cost of the shareholders. Here, the shareholders only refers to participate in the investment but does not manage the situation . At this point, the supervision cost mainly includes two aspects: one cost is that the shareholders monitor management, another cost is that shareholders monitor the other shareholders. First of all, the cost of monitoring management of shareholders reduce, because the existence of limited liability system, the company's operating risk is greatly reduced than unlimited liability, shareholders don't have to spend too much time and energy to monitor. Second, the cost of supervising other shareholders reduce, the reason is that if the investment in unlimited liability company, due to the unlimited joint and several liability for the debts of the constraints, investors must make decisions carefully. Monitoring costs will increase. In the limited liability company, there are professional managers, shareholder may don't know each other, they need to obtain the profit from the company only, do not need to supervise each other, this reduces the mutual supervision cost.

2.1.3Provide benefiting opportunities for shareholders. Under the limited liability system, the company's independent personality is the basis, it is like a layer of the veil, will isolate the creditors of the company and stakeholders, operators, etc. This provides the opportunities abusing independent company personality for shareholders. For their own benefit,company operators or shareholders, will use the company's independent personality by means of fraud ,even harming the interests of the company. Creditors normal demands has been cut off by limited liability system reasonably .

2.1.4Asylum shareholders to avoid debt.Limited liability system's organization is simple, convenient and quick, but it also has become one of its flawed incentives. Many people use it to speculative property management, hide or escape debts. In this performance, in reality, there are a lot of small and medium-sized companies using"one set ,number sign", the companies were independent of each other on the surface, in fact, these companies's many aspects such as the operation and management are often repeatedly. Once one company had a mistake in the operation, owes many debts, or faces bankruptcy case, it can also move assets to another company quickly. Obviously, in this process, the limited liability system has become the umbrella of asylum for shell companies, and the partial shareholders tools to avoid debt.

\subsection{The influence on the creditors.}

Before on the analysis of the influence on creditors, let's look at two examples.

Example 1: In Anhui,there is a taoyuan house property company founded in February 2003, the 
company's sales value achieve more than RMB 1 billion in 2004, there are more than 1000 employees, set up south, east, west, north, medium five marketing centers and more than 50 branches in Hefei, claimed that it realized to provide comfort and peace of mind, rest assured, worry, careful five "heart" level of service truly, is real estate agents in anhui carrier. However, on July 6, 2005, it announced collapse suddenly, company become a trace overnight. Many creditors quilt cover huge property, a lot of innocent people suffer from this event .

Example 2: In Fujian,a plastics factory owe a huge debt ratio above 100\%. In order to avoid debt,they announced bankruptcy maliciously. On trial, it made relation with the local government. After being declared bankruptcy, the court didn’t take any compulsory measures, business property increase or decrease freely; Although the creditors' meeting was held, but their opinions weren't accepted; When evaluating the bankruptcy property, they use hidden, interacting, and formed a "bankruptcy property which is insufficient to discharge the bankruptcy expenses". After the process the factory didn't subject to any losses, instead, it become no debts, and obtain business licenses and renamed business as usual. This process makes the creditor's rights damaged severely .

There are many instances in reality. Although, as a business body, the company should pursue more profit, but as a member of the social groups, their social responsibility is not ignored. This is the actual problems of the limited liability system.Because of such problems ,the limited liability system damage the interests of the creditors. In the limited liability company or joint stock company, a majority of shareholders can participate in the management directly or indirectly, some can understand the internal affairs; but creditors have no right to ask the company's general business and management. Once the company losses caused by operation mistakes or bankruptcy, shareholders is limited to their capital contribution ,only bears the liability for the debts of the company, creditors suffer losses ultimately. Obviously, the limited liability system protects the interests of shareholders, harms the interests of creditors.

\subsection{Impacts on the victim.}

Here, we start with an instance.

On February 12, 2009, the shijiazhuang people's court issued a civil verdict, sanlu declared bankruptcy ,it was China's top food industry, China top 500 enterprises, agricultural industrialization national key leading enterprise, the key support enterprise in shijiazhuang. On November 20, 2009, the shijiazhuang people's court end the sanlu bankruptcy procedures, because after compensation for Banks, it has no property. The bankruptcy of sanlu, creditor pay off to zero, which means that children don't get any compensation in the bankruptcy proceedings. It is painful in sanlu incident, the victim's future is worried. Although the government puts forward some solutions, amount of compensation is given to the victims, but it is still a drop in the ocean for the victims.

In real life, there are lots of such examples . In addition to the quality of the products, such as environmental pollution, medical accident, industrial accident and many other social problems have occurred, many people would be forced to become the victim. Obviously, limited responsibility system tend to ignore the demands of the victim. Because oft he existence of limited liability, when the company needs to compensation beyond its own assets, the victim doesn't get enough compensation usually. At this time, the limited liability became the tool of the company to evade responsibility. Therefore, the limited liability had given enough protection to the victim, it protected the interests of stakeholders only, and neglected the victim's requirements usually. If this things happen repeatedly, how can we achieve people-oriented truly? 


\subsection{Other role}

Of course, in addition to the influence of shareholders, creditors and the victim, there are some other influence of limited liability system cannot ignore in the economic life .

2.4.1 Promotes the separation of ownership and managerial authority, and promote the formation of modern enterprise system. In the unlimited liability company, both benefits and risks belong to the owners, the interest relationship is very concentrated. Because the owner must bear unlimited joint and several liability, therefore, the management become involved in owner's life, so the owner must master franchise personally. Of course, it also can't have such a case in modern enterprise system. In the limited liability company, stakeholders is responsible in the limit of responsible for the company's debts, the limitations of risk and uncertainty makes stakeholders don't have to participate in or control the operation and management personally, but employ professional managers, this mode of operation for the company can make fast decisions, is also the inevitable requirement of market economy. Thus, it promotes the separation of ownership and managerial authority, and also contributes to the formation of modern enterprise system.

2.4.2 Promotes the market transaction, optimizes the allocation of social resources. The investors (shareholders) have equity in capital contribution, are the one subject of property object property of all kinds of responsibility. Object refers to the property right relations, bear or carrier, is clear and disposable. Thus stake setting, trading means allocation and restructuring. Because of the characteristic of the limited liability, it will attract more investors, can scatter equity, limit risk, even if the investment failure the loss it is also within the scope of its capital contribution, it promotes the free transfer of shares, leads to the formation and development of the securities market, promotes the optimal allocation of social resources .

Analysis on the differences to every class of limited liability system, we can see that the system has many benefits to the shareholders (investors) groups, to stimulate the economy, to promote the formation of modern enterprise, but we also can see that not everyone will benefit from the system, the interests of the creditors and the victim is often overlooked. Whether can we deny limited liability system because of the different influence or negation? Next we will evaluate the system briefly and point out the further direction.

\section{Overall evaluation and future direction of limited liability system}

After analysis of the impacts of differences to all walks of life, this part will evaluate on system of limited liability, and point out the future direction.

\subsection{The overall evaluation}

From the above,we can seen that the limited liability system has both positive and negative influence. It has a positive role in promoting economic development, has many benefits to the shareholders (investors) groups, but it also has the inevitable shortcomings. Because of the shortcomings of limited liability system, some scholars affirmed its positive role in history ,at the same time, they thought that the limited liability system was not adapted to the market economy. They also put forward several propositions: first, the company should choose unlimited liability form, the shareholders is responsible to the company creditors, to ensure the benefit of creditors; second, the company should choose the form of unlimited liability and limited liability mixture, limited liability of shareholders are not involved in the company management directly,unlimited liability of shareholders can be involved in management directly; third, the company should take shared responsibility system in proportion, shareholders should take charge of creditors according to its share responsibility. These views negate limited liability system due to its negative effects. Admittedly,Limited liability system has some defects, is unfair to some groups, and with the 
improvement of the market economy, the investment environment is becoming more and more safer, more effective, more transparent, these defects of the limited liability system become obviously. But this paper argues that, we can't deny it because of the defects of the system , what's more, under other system these defects does not exist, so we should evaluate it overall.

3.2 In general, whether from the practice of foreign or domestic, limited liability system has played an indelible contribution to economic development . Despite the limited liability system has many defects, but his flaws. It was established as a long-term tested and modern company system, is the inevitable result of social development. Therefore, it pointed out that its shortcomings does't deny its existence value, is not to cancel the system, but in order to realize its value, to better the system, and to promote the development of the economy, then let the people share the reform development achievement.Therefore, under the condition of the market economy developed, in order to play the positive role of limited liability system effectively, the enterprise should balance social responsibility and the relationship between the economic interests, balance the relationship between the sponsors and other interest groups, the organic unification of limited liability and social responsibility, the limited liability system within the framework of integrated into the more social responsibility standards. Development in such a direction and limited liability system may be more perfect, play its positive role, it would promote the healthy and sustainable economy.

\section{References:}

[1] Ji wei Yu.Joint-stock introduction to economics[M].Shang hai: Fudan university press,1991, 11. [2] Jun hai Liu .Strengthening corporate social responsibility - to build an important content of modern enterprise system in our country[M].Commercial law in Samuel (2) ,Law press.,1997, 74.

[3] Zhen ya Cai.The defects of the system of modern enterprise co., LTD and make up for the countermeasures[J].Economic fabric, 2002, (1) , 44.

[4] Ya li Xia.Research on Limited liability system [J].PhD thesis of northwestern university,2005,(6), 18.

[5] Phillip I.Blumberg :The Law of Corporate Groups, Little Brown and Company, Boston andToronto, 1987.3. 